Check for updates

Cite this: RSC Adv., 2019, 9, 31306

Received 26th July 2019

Accepted 14th September 2019

DOI: $10.1039 / c 9 r a 05808 g$

rsc.li/rsc-advances

\section{Synthesis and characterization of sulfonated mesoporous NiO-ICG core-shell solid sphere catalyst with superior capability for methyl ester production}

\author{
Soroush Soltani, (D) *a Nasrin Khanian, ${ }^{\mathrm{b}}$ Umer Rashid ${ }^{\mathrm{c}}$ and Thomas Shean Yaw \\ Choong $^{\mathrm{a}}$
}

In the present research, a mesoporous $\mathrm{NiO}$ core-shell solid sphere was hydrothermally synthesized, using polyethylene glycol (PEG; 4000) as a surfactant and incomplete carbonized glucose (ICG) as a template. Then, thermal decomposition of ammonium sulphate was employed to convert the as-synthesized material to sulfonated mesoporous NiO-ICG catalyst, in order to accelerate conversion of waste cooking palm oil (WCPO) into ester. The structural, textural, morphological, and thermal characteristics of the synthesized sulfonated mesoporous NiO-ICG catalyst were evaluated using X-ray diffraction (XRD), Raman spectroscopy, temperature programed desorption (TPD), Brunauer-Emmet-Teller (BET), thermogravimetric analysis (TGA), and transmission electron microscopy (TEM). Furthermore, the effect of different reaction parameters against reaction time were investigated. Under the optimal transesterification conditions; catalyst loading of $1 \mathrm{wt} \%$, methanol to WCPO ratio of $9: 1$, operation temperature of $100{ }^{\circ} \mathrm{C}$ and mixing intensity of $450 \mathrm{rpm}$, an optimum ester yield of $95.6 \%$ was achieved. Additionally, a recyclability study proved that the spent catalyst was highly potential to be reused for nine successive transesterification reactions without further treatment. Finally, the physicochemical characteristics of the produced WCPO methyl ester were evaluated which were highly in accordance with both European (EN; 14214) and American Standards for Testing Materials (ASTM; D6751) specifications.

\section{Introduction}

Recently, biodiesel has been nominated as a promising biodegradable source of energy to overcome the diminution of petrochemical fuels. ${ }^{\mathbf{1}}$ Biodiesel possesses unique characteristics close to petroleum-based fuels in terms of cetane value, flash point and kinematic viscosity. ${ }^{2}$

Biodiesel production can be classified into homogeneous or heterogeneous catalysis reactions regarding on the type of feedstock. Those of catalysis methods are further divided into base or acid catalysts. At the moment, homogeneous basic catalysts are conventionally being used for the synthesis of fatty acid methyl ester (FAME). In contrast with acidic catalysts, base catalysts require lower operating temperature $\left(25-70{ }^{\circ} \mathrm{C}\right)$ in order to enhance reaction rate at atmospheric pressure..$^{\mathbf{3 , 4}}$ Unluckily, homogeneous basic catalysts generate a certain amount of water, even in the presence of water-free raw

${ }^{a}$ Department of Chemical and Environmental Engineering, Universiti Putra Malaysia, 43400 Selangor, Malaysia.E-mail: soroush.soltaani@gmail.com

${ }^{b}$ Department of Physics, Islamic Azad University, Karaj, Iran

${ }^{c}$ Institute of Advanced Technology, Universiti Putra Malaysia, 43400 Selangor, Malaysia materials, due to the interaction between alcohol and hydroxides. The generation of even a small amount of water consequently leads to formation of soap. The saponification drops the FAME yield and causes a complicated process of separation and thus boosts the cost of ester production. On the other side, the use of heterogeneous solid acid catalysts has fascinated scientific attentions because of elimination of soap formation. It also simplifies the separation process which subsequently reduces the operation cost. Moreover, the heterogeneous solid-acid catalysts are highly potential to catalyze both transesterification and esterification of feedstocks containing high free fatty acids (FFAs) ${ }^{5,6}$ Indeed, using heterogeneous solid acid catalysts can efficiently eliminate using of two steps process of ester generation including basic catalysis transesterification and acid catalysis esterification reactions. It should be noted that diffusion of the polar by-products to the surface of the catalyst causes deactivation of the catalyst. ${ }^{7}$ Moreover, solid acid catalysts are simply regenerated and recycled in comparison with homogenous base/acid catalysts. ${ }^{8}$ As a consequence, the reusable eco-friendly solid acid catalysts are potential to be replaced with environmentally unfriendly homogeneous acid/ base catalysts. ${ }^{9}$ 
Heterogeneous acid catalysts are categorized into three major groups including: ion-exchange resin, metal and carbonbased catalysts. On the other hand, the most of these catalysts are not proper for transesterification of feedstocks because of several undesired limitations such as low specific surface area (SSA), low porosity and poor mechanical/thermal stabilities. ${ }^{\mathbf{1 0}}$

Recently, a new generation of sulfonated carbon-based solid acid catalysts have been synthesized (through either the sulfonation of a carbonized inorganic/organic compound or carbonization of sulfopolycyclic aromatic hydrocarbons) as potential catalysts for ester production. However, these classes of catalysts are highly stable and active via catalysis reaction, they possess a soft aggregation of polycyclic aromatic hydrocarbons. Having no rigid carbon sources may cause leaching of the $-\mathrm{SO}_{3} \mathrm{H}$ from the active sites of the catalyst. In case of transesterification of triglyceride over high temperature, applying carbon materials with soft aggregation of polycyclic aromatic hydrocarbons is not suitable where the protonation of the carbonyl group of a triglyceride is difficult. ${ }^{\mathbf{1 1}}$

Nevertheless, the sulfonated mesoporous metal oxide catalysts can be potential candidates to overcome these limitations due to possessing rigid aggregation of polycyclic aromatic hydrocarbons. These materials are highly attracting because of their other unique characteristics such as large surface area, adjustable pore size, and high thermal steadiness. The combination of these characteristics increases the penetration of the reactants easily to the active sites which consequently increases the rate of production. ${ }^{\mathbf{1 1}, 12}$ Moreover, sulfonated mesoporous metal oxide catalyst prevents agglomeration of the molecules of water around the active sites that significantly improves the yield of final product.

Furthermore, attempts have been made to maximize the activity and selectivity of these materials through either in situ or post-functionalization of the high interior surface areas and internal frameworks of mesostructured in presence of specific organic/inorganic components (prior to post-sulfonation treatment). One route to modify textural characteristics of mesoporous materials is simultaneously incorporation of desire functional components ( $\mathrm{Al}, \mathrm{Zn}, \mathrm{Cu}, \mathrm{Ni}, \mathrm{Ti}$, etc) into mesostructured materials. More recently, the performance of $\mathrm{Ni}$ as support on carbon materials for the deoxygenation of plant oil into hydrocarbon-fuel has been reviewed. The Ni-based catalysts have demonstrated high activity and great selectivity due to their superior properties. ${ }^{\mathbf{1 3 , 1 4}}$ In a recent research work, various Ni loadings (5 wt\% Ni, $10 \mathrm{wt} \% \mathrm{Ni}, 40 \mathrm{wt} \% \mathrm{Ni}$ and $100 \mathrm{wt} \% \mathrm{Ni}$ ) was applied as support on hexagonal mesoporous silica (HMS) for deoxygenation of triolein into hydrocarbon-biofuel production. ${ }^{15}$ According to the experiment results, $10 \mathrm{wt} \%$ Ni loading gave $92.5 \%$ and $95.2 \%$ of conversion and selectivity rates, respectively. The excellent catalytic performance was assigned to the excellent textural properties (surface area of $512 \mathrm{~m}^{2} \mathrm{~g}^{-1}$ and pore size of $5.39 \mathrm{~nm}$ ) of the catalyst and uniformly dispersion of Ni particles on the HMS ( $\mathrm{Si}-\mathrm{O}-\mathrm{Ni}$ ).

In the present work, a sulfonated mesoporous NiO-ICG catalyst was hydrothermally synthesized and then postfunctionalized using thermal decomposition of ammonium sulphate. The main advantage of core-shell nanoparticles is to simultaneously enhance thermal stability and reduce reactivity of the core materials due to the shell material coating. Besides, the shell material can provide surface chemistry for further modification and functionalization of the nanoparticles. Ni was selected as a dynamic support to stabilize the as-synthesized mesostructured ICG, to increase penetration of guest particles into the active sites (due to the high mass transfer) which subsequently accelerated the transesterification of WCPO. The catalytic performance and recyclability of the synthesized catalysts were examined through transesterification of waste cooking palm oil (WCPO) using autoclave reactor. Finally, the physicochemical qualities of the produced ester were assessed and then compared with both of ASTM; D6751 and EN; 14214 specifications.

\section{Materials and methods}

\subsection{Materials}

The analytical reagents; nickel nitrate $\left[\mathrm{Ni}\left(\mathrm{NO}_{3}\right)_{2} \cdot 6 \mathrm{H}_{2} \mathrm{O}\right]$, polyethylene glycol [PEG, $\mathrm{C}_{2 n} \mathrm{H}_{4 n+2} \mathrm{O}_{n+1}, M_{n}=4000 \mathrm{~g} \mathrm{\textrm {mol } ^ { - 1 }}$ ], methanol $\left(\mathrm{CH}_{3} \mathrm{OH} ; \geq 99.5 \%\right)$, and ethanol $\left(\mathrm{C}_{2} \mathrm{H}_{6} \mathrm{O} ; \geq 99.5 \%\right)$ were purchased from Fisher Scientific. Urea $\left[\mathrm{CO}\left(\mathrm{NH}_{2}\right)_{2}\right]$, Dglucose $\left(\mathrm{C}_{6} \mathrm{H}_{12} \mathrm{O}_{6}\right)$, and ammonium sulphate $\left[\left(\mathrm{NH}_{4}\right)_{2} \mathrm{SO}_{4}\right.$; $\geq 99.5 \%$ ] were purchased from Sigma-Aldrich. The standard methyl esters for GC analysis, consist of heptadecanoate, methyl palmitate, methyl oleate, methyl myristate, methyl stearate, and methyl linoleate were provided by fluke, USA.

The WCPO containing $\mathbf{1 7 . 0} \%$ FFA was supplied by local market, Malaysia. All the physicochemical characteristics of the WCPO are characterized by AOCS method and summarized in Table 1. From GC-MS analysis, the used oil contained five major FFAs including palmitic acid $\left(\mathrm{C}_{16: 0}, 34.80 \%\right)$, linoleic acid $\left(\mathrm{C}_{18: 2}\right.$, $12.59 \%)$, oleic acid $\left(\mathrm{C}_{18: 1}, 42.78 \%\right)$, stearic acid $\left(\mathrm{C}_{18: 0}, 7.13 \%\right)$, and myristic acid $\left(\mathrm{C}_{14: 0}, 2.70 \%\right)$.

\subsection{Preparation of mesoporous $\mathrm{SO}_{3} \mathrm{H}-\mathrm{NiO}-\mathrm{ICG}$ catalyst}

2.2.1. Preparation of incomplete carbon glucose (ICG). The pyrolysis process was performed in a muffle furnace tube where $10 \mathrm{~g}$ of $\mathrm{D}$-glucose was positioned in a ceramic boat and then loaded into the furnace. The pyrolysis was set from room temperature to $400{ }^{\circ} \mathrm{C}$ for $12 \mathrm{~h}$ with nitrogen $\left(\mathrm{N}_{2}\right)$ gas flow rate at $100 \mathrm{~mL} \mathrm{~min}^{-1}$ to produced ICG. Next, the sample was cooled at room temperature, followed by milling at $1000 \mathrm{rpm}$ for $1 \mathrm{~h}$ to form homogenized fine powder. The precursor was then pounded to powder form for further modifications.

Table 1 Physicochemical properties of the spent WCPO by AOCS method

\begin{tabular}{lll}
\hline Quality & Unit & WCPO \\
\hline Acid value & $\mathrm{mg} \mathrm{KOH} \mathrm{per} \mathrm{g}$ & 34.0 \\
Saponification value & $\mathrm{mg} \mathrm{KOH}$ per g & 171.0 \\
Density $\left(15^{\circ} \mathrm{C}\right)$ & $\mathrm{g} \mathrm{cm}^{-3}$ & 0.91 \\
Kinematic viscosity $\left(40^{\circ} \mathrm{C}\right)$ & $\mathrm{mm}^{2} \mathrm{~s}^{-1}$ & 33.0 \\
Free fatty acid & $\%$ & 17
\end{tabular}


2.2.2. Preparation of mesoporous NiO-ICG catalyst. A polymeric mesoporous $\mathrm{NiO}$ catalyst was initially generated using autoclave-assisted method. ${ }^{16}$ The optimum hydrothermal conditions were found to be: $\mathrm{Ni}\left(\mathrm{NO}_{3}\right)_{2}$ of $2 \mathrm{~g}$, urea of $5 \mathrm{mmol}$, ICG : metal ratio of $5: 1$, PEG of $15 \mathrm{~g}$, and deionized water of $150 \mathrm{~mL}$. Then, the mixture was transferred into the Teflon-lined stainless-steel autoclave. Next, the autoclave was sealed and maintained at $200{ }^{\circ} \mathrm{C}$ for $18 \mathrm{~h}$ under autogenous pressure. The formed powder was further annealed at $600{ }^{\circ} \mathrm{C}$ for $4 \mathrm{~h}$ under $\mathrm{N}_{2}$ flow gas to eradicate residual volatiles along the process through decomposition of the initial materials.

2.2.3. Sulfonation by thermal decomposition of ammonium sulphate. The post-sulfonation treatment is a well-known approach to modify the nature of the parent materials by increasing the aromatic chains and decreasing the aliphatic rings. Typically, it enhances the hydrophobic nature of the materials, particularly, near the active sites. The prefabricated mesoporous NiO-ICG material was sulfonated through thermal decomposition of ammonium sulphate. In this procedure, $2 \mathrm{~g}$ of synthesized NiO-ICG was dispersed in $50 \mathrm{~mL}$ of $\left(\mathrm{NH}_{4}\right)_{2} \mathrm{SO}_{4}$ reagent and sonicated for $1 \mathrm{~h}$. Then, the mixture was immediately poured into the Teflon lined stainless steel autoclave. Next, the autoclave was sealed and maintained at $200{ }^{\circ} \mathrm{C}$ for $30 \mathrm{~min}$. Next, the sample was washed with mixture of deionized water and ethanol to eradicate organic moieties on the surface. The sample was then dried out at $100{ }^{\circ} \mathrm{C}$ for $24 \mathrm{~h}$ in an electrical vacuum oven. Finally, the sulfonated mesoporous NiO catalyst was fully activated through post-annealing treatment at $600{ }^{\circ} \mathrm{C}$ for $4 \mathrm{~h}$ under $\mathrm{N}_{2}$-flow gas. The final product; sulfonated mesoporous NiO-ICG catalyst was prepared in large scale for further examinations.

\subsection{Catalyst characterization}

The pore distribution diameters and specific surface areas were assessed by Barrett-Joyner-Halenda (BJH) and adsorptiondesorption isotherm methods, respectively using Thermo Finnigan apparatus. Initially, the procedure started by elimination of water and degassing of the sample through preheating of samples at $150{ }^{\circ} \mathrm{C}$ for $2 \mathrm{~h}$ under hydrogen flow. Then the sample tube was immersed into a gaseous container of $\mathrm{N}_{2}\left(-196{ }^{\circ} \mathrm{C}\right)$. The amount of $\mathrm{N}_{2}$ adsorption was computing to the relative pressure. Raman spectroscopy was employed to study structural features of the synthesized mesoporous $\mathrm{SO}_{3} \mathrm{H}-\mathrm{NiO}-\mathrm{ICG}$ catalyst, using a Renishaw Raman spectrometer with $514 \mathrm{~nm}$ laser excitation. X-ray diffraction (XRD; 6000 Shimadzu) patterns were obtained with a scanning range of 10-80 degree at a scanning rate of 2 degree per min across a metal target (copper) with wavelength of $0.154 \mathrm{~nm}$. Ammonia temperatureprogrammed desorption ( $\mathrm{NH}_{3}-\mathrm{TPD}$; Thermo Finnigan TPDRO 1100) equipped with a thermal conductivity detector (TCD) was employed to investigate the nature and acidity of the sites. In this procedure, $0.4 \mathrm{~g}$ of the mesoporous catalyst was initially treated under flowing argon gas at $150{ }^{\circ} \mathrm{C}$. Then, the catalyst was exposed to a continual flow of $\mathrm{NH}_{3}$ for $1 \mathrm{~h}$. Lastly, the overall volume of adsorbed $\mathrm{NH}_{3}$ was measured through heating the sample up to $900{ }^{\circ} \mathrm{C}$ via TCD with a heating rate of $15{ }^{\circ} \mathrm{C} \mathrm{min}{ }^{-1}$

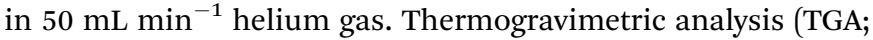
TG-50 Mettler) was applied to assess the mass-losses of the functional groups over the surface of the synthesized sulfonated mesoporous NiO-ICG catalyst. The TGA experiment was carried out from room temperature to the maximum of $1000{ }^{\circ} \mathrm{C}$ in airflow of $200 \mathrm{~mL} \min ^{-1}$ with the rate $10{ }^{\circ} \mathrm{C} \min ^{-1}$. The microscopic morphology of the synthesized catalyst was examined by transmission electron microscopy (TEM, Hitachi $\mathrm{H}$ 7100) with electron beam energy of 100-200 keV. Prior to TEM analysis, the sample was transferred to a glove box to inhibit being exposed to air.

\subsection{Transesterification reaction}

Prior to set up transesterification reaction, the WCPO feedstock was pre-treated in order to eliminate the presence of moisture and other residues. In this regard, the prepared WCPO was heated up at $120{ }^{\circ} \mathrm{C}$ for $20 \mathrm{~min}$ and then filtered. Then, the transesterification mixture consisting of the mesoporous $\mathrm{SO}_{3} \mathrm{H}-$ NiO-ICG catalyst, WCPO and methanol was placed into an autoclave reactor which was equipped with an electronic time controller, electronic heater and magnetic stirrer. Hydrothermal-autoclaving technique is known as one of the greenest process as the operation can be taken place under a sealed system condition. This method can provide high conversion rate under high temperature and high pressure (HTHP) conditions at a shorter reaction time. Besides, a hydrothermal condition provides higher interface between reactants, results in higher mass transfer. ${ }^{\mathbf{1 7}}$ Under the HTHP system, hydrogen atoms attached to the surface of the catalyst cleave and subsequently link with FFAs, continues with catalysing into methyl ester (ME). ${ }^{\mathbf{1 2}}$

The preliminary transesterification was carried out at a nonoptimized transesterification conditions: catalyst amount of $1 \mathrm{wt} \%$, methanol to WCPO molar ratio of $6: 1$, operating temperature of $80{ }^{\circ} \mathrm{C}$, and mixing intensity of $300 \mathrm{rpm}$. At the end of each transesterification reaction, the sample was centrifuged to separate the catalyst from other liquid parts. Finally, remaining amount of the methanol was evaporated, and then the rest was placed into a separating funnel to separate synthesized ester from glycerol.

The EN 14103 standard method was introduced to determine the content of produced ester. The EN 14103 standard is a method which typically applied for calibration of the FAME by relative reply to an internal standard. The biodiesel yield was evaluated by gas chromatography flame ionization detector (GC-FID; Agilent 7890A). The methyl heptadecanoate was utilized as an internal-standard while methyl stearate, methyl myristate, methyl oleate, methyl palmitate, and methyl linoleate were used as reference-standards. The yield of conversion was evaluated via eqn (1): ${ }^{18}$

$$
C=\frac{\sum A \times \sum A_{\mathrm{meh}}}{A_{\mathrm{meh}}} \times \frac{C_{\mathrm{meh}} \times V_{\mathrm{meh}}}{\mathrm{Wt}} \times 100 \%
$$

where; $C$ is the percentage of ester yield, $\sum A$ is the summation of full area for the FFA peaks, $A_{\text {meh }}$ is peak area of internalstandard, $C_{\mathrm{meh}}$ is the total loading of the methyl 
heptadecanoate, $V_{\text {meh }}$ is the total volume of the methyl heptadecanoate, and $\mathrm{Wt}$ is the mass of the produced FAME.

\section{Results and discussions}

\subsection{Catalyst characterization}

The $\mathrm{N}_{2}$ adsorption-desorption isotherm and pore diameter allocation of the synthesized sulfonated mesoporous NiO-ICG catalyst are displayed in Fig. $1 \mathrm{~A}$ and $\mathrm{B}$, respectively. In accordance with Brunauer, Deming, Deming, and Teller (BDDT) isotherm categorization, the shape of $\mathrm{N}_{2}$ adsorption/desorption isotherm was of typical as type IV, confirming the mesopore structure of the synthesized sulfonated mesoporous NiO-ICG catalyst. ${ }^{19}$ At the initial part of the isotherm $\left(P / P_{\mathrm{o}}<0.4\right)$, a weak $\mathrm{N}_{2}$ adsorption was observed while at the middle part $\left(P / P_{\mathrm{o}}>0.4\right)$, the adsorption increased which evidenced the presence of monomodal mesopore size distribution. However, at the end part of the isotherm $\left(P / P_{\mathrm{o}}>0.8\right)$, adsorption/desorption overlapped to gain shape a tale which might be corresponded to the slits between ICG and NiO nanoparticles. Fig. 1B confirms that the pores diameter was monomodal with a sharp curve at $3.1 \mathrm{~nm}$. All the studied textural characteristics are displayed in Table 2 .
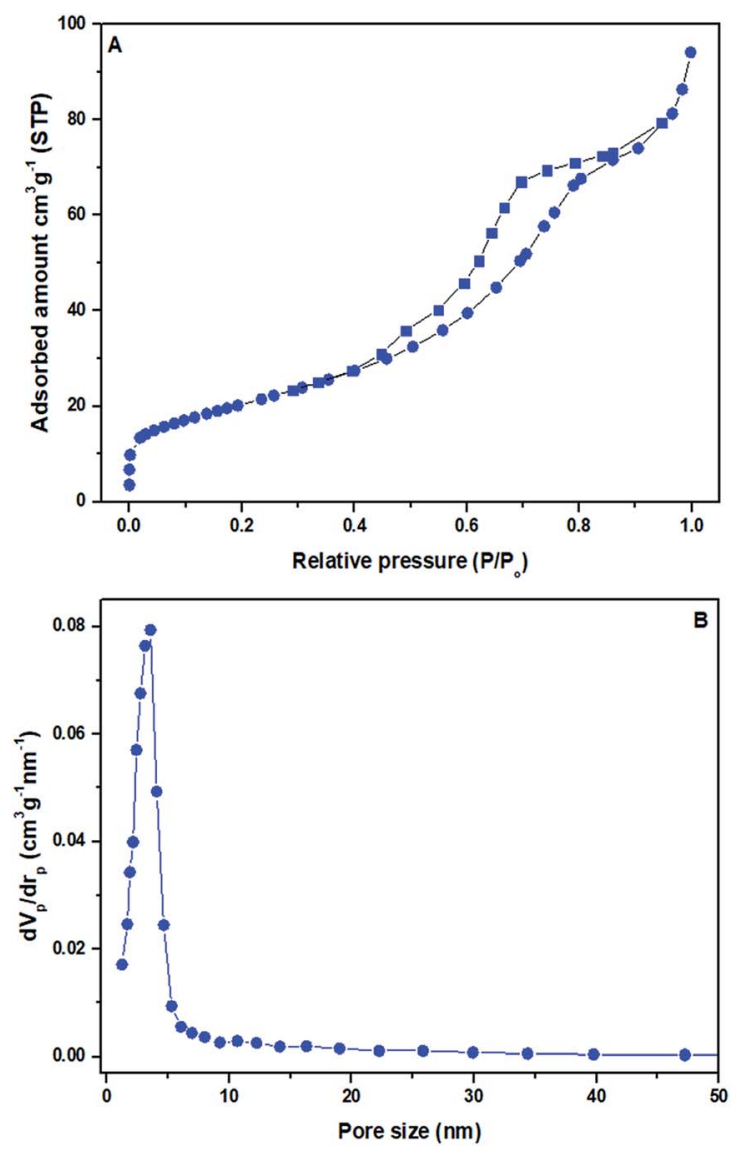

Fig. 1 (A) Adsorption /desorption ) isotherm, and (B) pore diameter distributions of the prepared sulfonated mesoporous $\mathrm{NiO}-$ ICG catalyst.
Table 2 Some textural characteristics of prepared mesoporous $\mathrm{SO}_{3} \mathrm{H}-\mathrm{NiO}-\mathrm{ICG}$ catalyst

\begin{tabular}{lcccc}
\hline Catalyst & ${ }^{a} \mathrm{SSA}$ & ${ }^{b} D_{\mathrm{p}}$ & ${ }^{c} V_{\mathrm{p}}$ & ${ }^{d} \mathrm{NH}_{3}$ acidity density \\
\hline $\mathrm{SO}_{3} \mathrm{H}-\mathrm{NiO}-\mathrm{ICG}$ & 411 & 3.1 & 0.13 & $3.10 \pm 0.05$ \\
${ }^{a}$ Specific surface area $\left(\mathrm{m}^{2} \mathrm{~g}^{-1}\right) .{ }^{b}$ Average pore diameter $(\mathrm{nm}) .{ }^{c}$ Total \\
pore specific volume at $\mathrm{P} / P_{\mathrm{O}}=0.99\left(\mathrm{~cm}^{3} \mathrm{~g}^{-1}\right) .{ }^{d}$ Based on $\mathrm{NH}_{3}$-TPD \\
measurements $\left(\mathrm{mmol} \mathrm{g}^{-1}\right)$.
\end{tabular}

The structural feature of the prepared sulfonated mesoporous NiO-ICG catalyst was investigated using Raman spectroscopy system. Fig. 2A shows Raman spectra verified in the spectral range of $1000 \mathrm{~cm}^{-1}$ to $2500 \mathrm{~cm}^{-1}$. The Raman spectra of the sulfonated mesoporous NiO-ICG catalyst demonstrated a strong $\mathrm{G}$ peak at $1575 \mathrm{~cm}^{-1}$ which was corresponded to $\mathrm{E}_{2 \mathrm{~g}}$ mode scattering of phonon of the $\mathrm{sp}^{2} \mathrm{C}$ atoms. ${ }^{20}$ Besides, an expanded D peak verified at $1352 \mathrm{~cm}^{-1}$ which was attributed to K-point phonons of $\mathrm{A}_{1 \mathrm{~g}}$ equilibrium. ${ }^{21,22}$

Fig. 2B depicts the progress of the crystallization of the sulfonated mesoporous NiO-ICG catalyst. As clearly can be seen, major X-ray diffraction peaks of (111), (200), (220), and
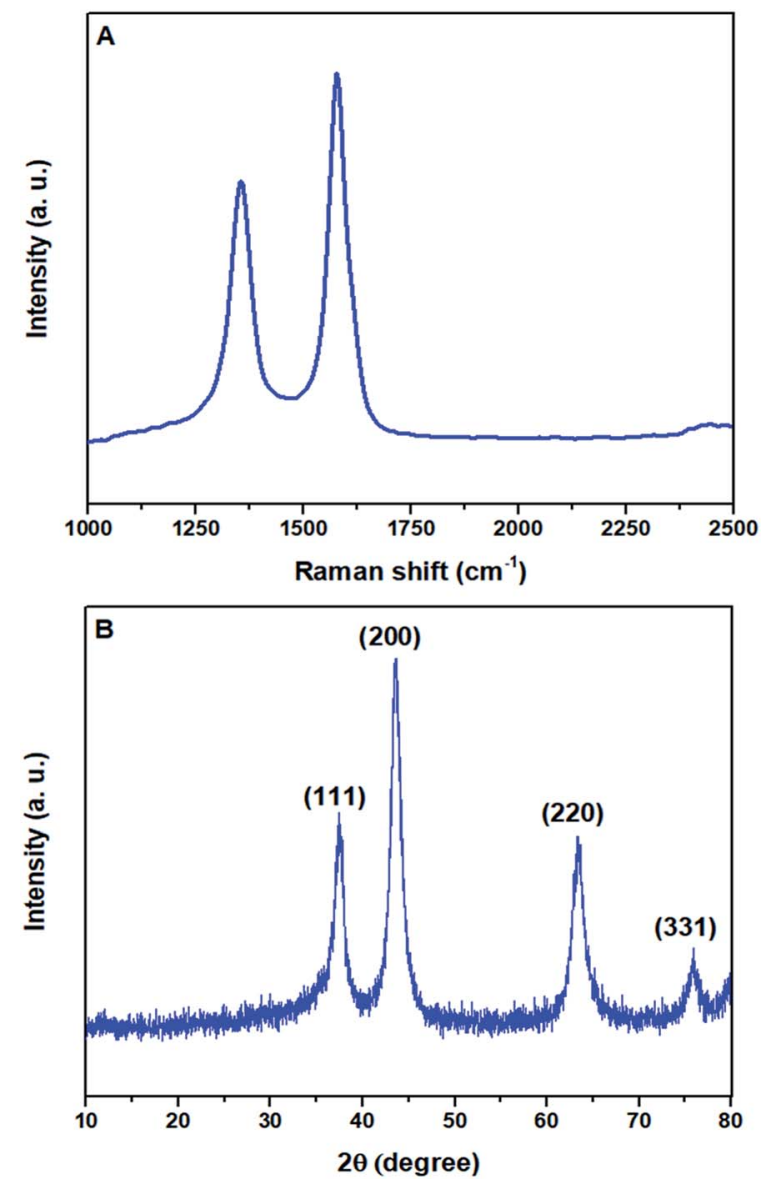

Fig. 2 (A) Raman spectra of the sulfonated mesoporous NiO-ICG catalyst; (B) XRD pattern of the sulfonated mesoporous NiO-ICG catalyst. 
(331) were detected at $37.54^{\circ}, 43.48^{\circ}, 63.60^{\circ}$, and $75.80^{\circ}$, respectively. The X-ray diffraction peaks were perfectly matched to the cubic phase NiO nanoparticles (JCPDS card no. \#471049). ${ }^{23,24}$ In the XRD pattern, no other crystalline phases appeared which was corresponded to the high purity of the cubic phase NiO nanoparticles.

The $\mathrm{NH}_{3}$-TPD profile of the sulfonated mesoporous NiO-ICG catalyst is displayed in Fig. 3A. The two distinctive peaks were observed on the profile. The first $\mathrm{NH}_{3}$ desorption was detected at around $540{ }^{\circ} \mathrm{C}$ which was associated to the presence of weak acid as a result of decomposition of carboxyl groups. ${ }^{25}$ The second $\mathrm{NH}_{3}$ desorption was detected at $730{ }^{\circ} \mathrm{C}$ which was assigned to the existence of strong acid as a result of decomposition of sulfonic groups. ${ }^{26}$ As indicated in Table 2, the sulfonated mesoporous NiO-ICG catalyst possessed $\mathrm{NH}_{3}$ acidity of $3.10 \mathrm{mmol} \mathrm{g}^{-1}$.

Fig. 3B depicts TGA and DTA curves of sulfonated mesoporous NiO-ICG catalyst. Three endothermic curves were detected in the DTA plot from room temperature to $100{ }^{\circ} \mathrm{C}$, $100{ }^{\circ} \mathrm{C}$ to $350{ }^{\circ} \mathrm{C}$, and $350{ }^{\circ} \mathrm{C}$ to $450{ }^{\circ} \mathrm{C}$ which were assigned to the adsorption of molecules of water, carbon and sulfonic compounds, respectively. ${ }^{26,27}$ Obviously, no other exothermic curve took place at temperature above $450{ }^{\circ} \mathrm{C}$ to confirm recrystallization of NiO spinal.

The strategy for synthesizing $\mathrm{SO}_{3} \mathrm{H}-\mathrm{NiO}-\mathrm{ICG}$ core-shell solid sphere catalyst is represented in Fig. 4. Initially, NiO-ICG coreshell solid sphere precursor was prepared through a simplistic hydrothermal-assisted method along with post-calcination treatment. It is assumed that during the reaction, NiO nanoparticles were predominantly situated around the hydrophilic shell of the ICG as the template (carbon spheres). The subsequent post-sulfonation treatment was performed to functionalize mesopore channels with sulfonic compounds.

The morphology of the synthesized sulfonated mesoporous NiO-ICG catalyst was examined by the TEM image (shown at Fig. 4 (left corner image)). The formation of carbon core spheres and distribution of NiO nanoparticles were displayed in black and gray colors, respectively.

\subsection{Effect of reaction parameters on the conversion yield}

To optimize the transesterification conditions, the impact of various factors (such as catalyst loading, the carbon length of alcohol, and alcohol to oil molar ratio, operating temperature and mixing intensity) on the yield of produced FAME were evaluated, where the reaction time was untouched.

3.2.1. Effect of catalyst concentration. It should be noted that esterification reaction is a reversible reaction and thus, catalyst dosage should be sufficient to catalyse both the reaction and the converse reaction. However, further amount of catalyst may increase the viscosity of the mixture and subsequently decrease mass transfer. ${ }^{28,29}$ The impact of the sulfonated mesoporous NiO-ICG catalyst over ester production was carried out through different experiments over different loading of the catalyst $(0.25,0.5,0.75,1.00,1.25$, and $1.50 \mathrm{wt} \%)$. In the preliminary stage, the methanol to WCPO molar ratio, reaction temperature and mixing intensity were $6: 1,80^{\circ} \mathrm{C}$ and $300 \mathrm{rpm}$, respectively. Fig. 5 depicts the effect of different loading of the sulfonated mesoporous NiO-ICG catalyst on the FAME yield against reaction time. Obviously, loading higher concentration of the catalyst from $0.25 \mathrm{wt} \%$ to $1.00 \mathrm{wt} \%$, resulted in the highest ester yield. It was corresponded to increasing the number of active sites and surface contacts by increasing the dosage of the catalyst. However, the conversion rate level off upon higher mesoporous catalyst concentrations as it was expected and mentioned above. Thereby, the optimal dosage of the catalyst was found over $1.00 \mathrm{wt} \%$, which was considered in further experiments.

3.2.2. Effect of the carbon length of the alcohol. Both of methanol and ethanol are vastly being used for transesterification reaction. However, biodiesel production in presence of the ethanol is eco-friendlier, methanol is the most favourite alcohol because of its polar aspects. ${ }^{29}$ Fig. 6 depicts the effect of alcohol type on transesterification of WCPO over $1.0 \mathrm{wt} \%$ of the synthesized sulfonated mesoporous NiO-ICG catalyst. It was clarified that the FAME yield obtained in presence of methanol was quite higher when compared with ethanol. Obviously, the reaction rate with ethanol was slower as
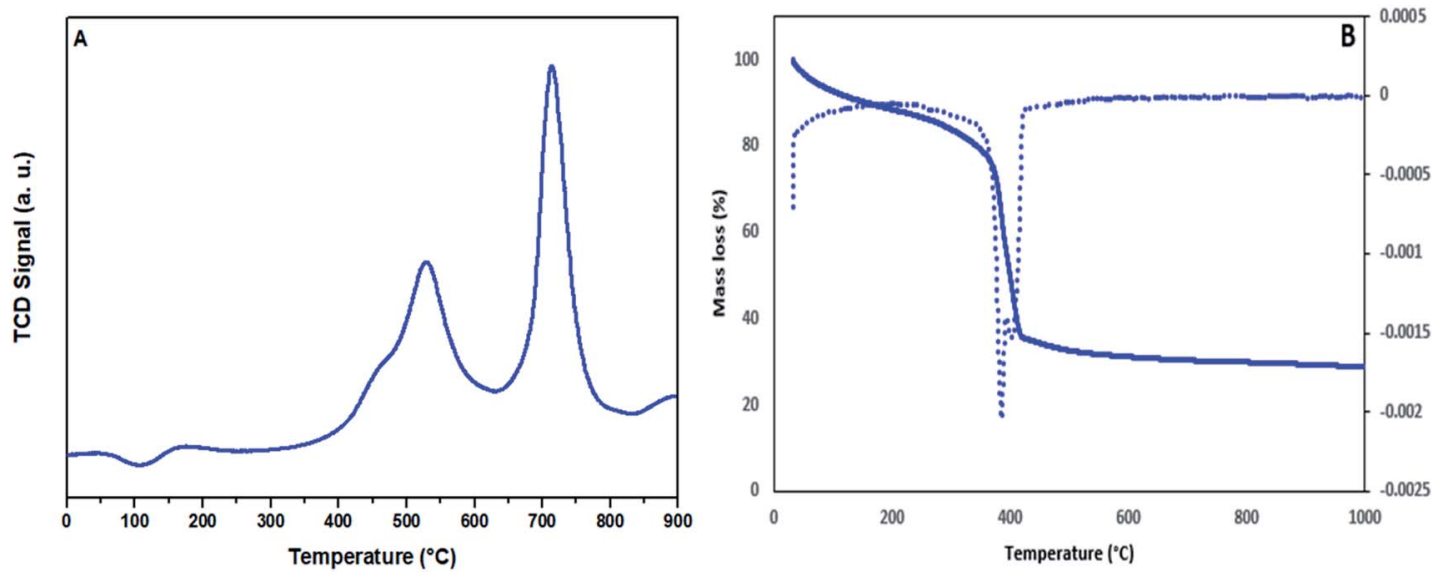

Fig. 3 (A) Typical $\mathrm{NH}_{3}$-TPD profile of the synthesized sulfonated mesoporous NiO-ICG catalyst; (B) DTA-TGA curves of the sulfonated mesoporous $\mathrm{NiO}-\mathrm{ICG}$ catalyst. 

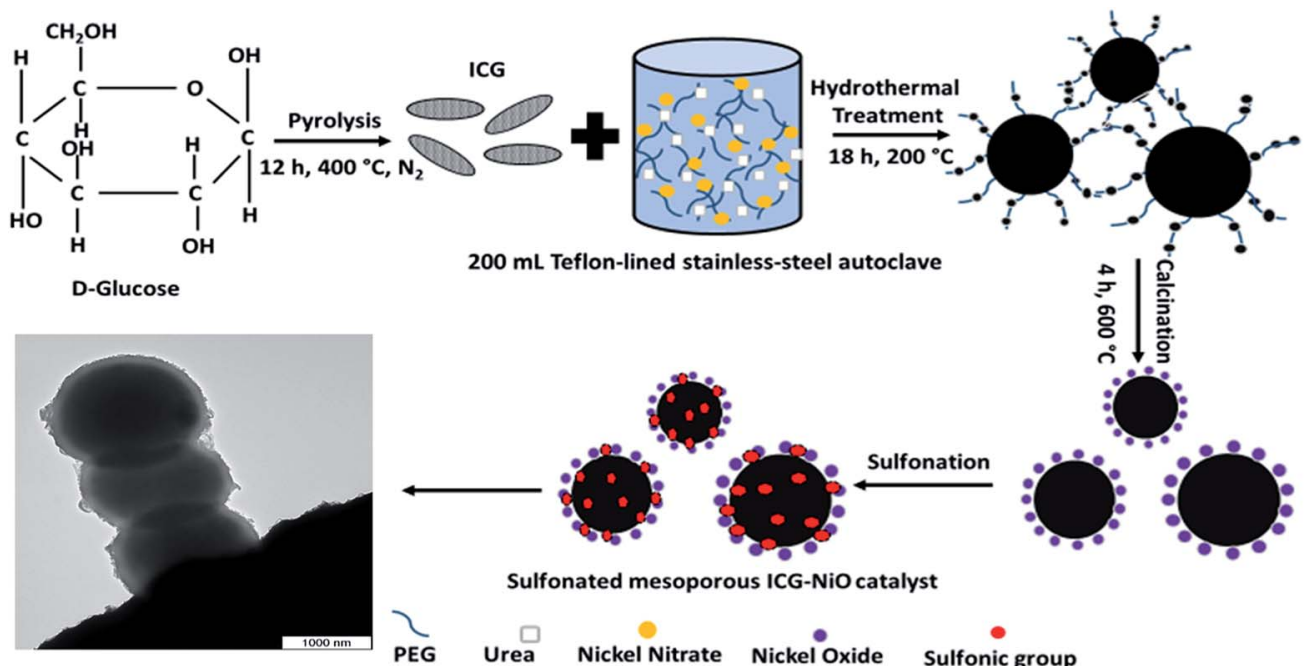

Urea Nickel Nitrate Nickel Oxide Sulfonic group

Fig. 4 Schematic illustration of the formation of $\mathrm{SO}_{3} \mathrm{H}-\mathrm{NiO}-\mathrm{ICG}$ core-shell solid sphere catalyst; TEM image of the synthesized sulfonated mesoporous $\mathrm{NiO}-I C G$ catalyst (left corner image).

compared with methanol. This behaviour might be assigned to the carbon length of the used alcohol. Furthermore, the effect of methyl nucleophile was stronger than the ethyl nucleophile, resulted in lower reaction rate. Similar results were reported in previous researches. ${ }^{30,31}$ By drawing on the results, methanol was found to be more potential to methanolized the WCOP to methyl ester over the synthesized sulfonated mesoporous NiOICG catalyst.

For evaluating the impact of different alcohol to oil molar ratio, five experiments were conducted with different alcohol: WCPO molar ratio $(1: 3,1: 6,1: 9,1: 12$, and $1: 15)$, while the catalyst concentration was $1.00 \mathrm{wt} \%$, the reaction temperature was $80{ }^{\circ} \mathrm{C}$ and the stirring intensity was $300 \mathrm{rpm}$. The conversion yield was reached to its highest value by increasing alcohol to oil molar ratio to $9: 1$ and $12: 1$ for methanol and ethanol, respectively. Based on a chemical dynamic setting,

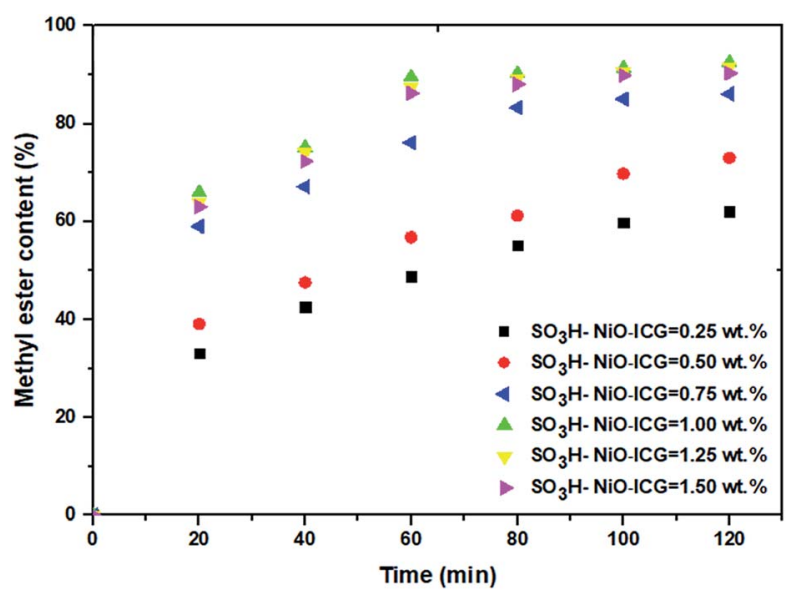

Fig. 5 The effect of the sulfonated mesoporous NiO-ICG catalyst dosage on the FAME yield versus operating time $(\mathrm{MeOH}$ : WCPO molar ratio, reaction temperature and mixing intensity were $6: 1,80^{\circ} \mathrm{C}$ and 300 rpm, respectively). a rise in the amount of alcohol accelerated the conversion rate. However, excess amount of alcohol did not improve the FAME yield which might be due to the fact that glycerol separations
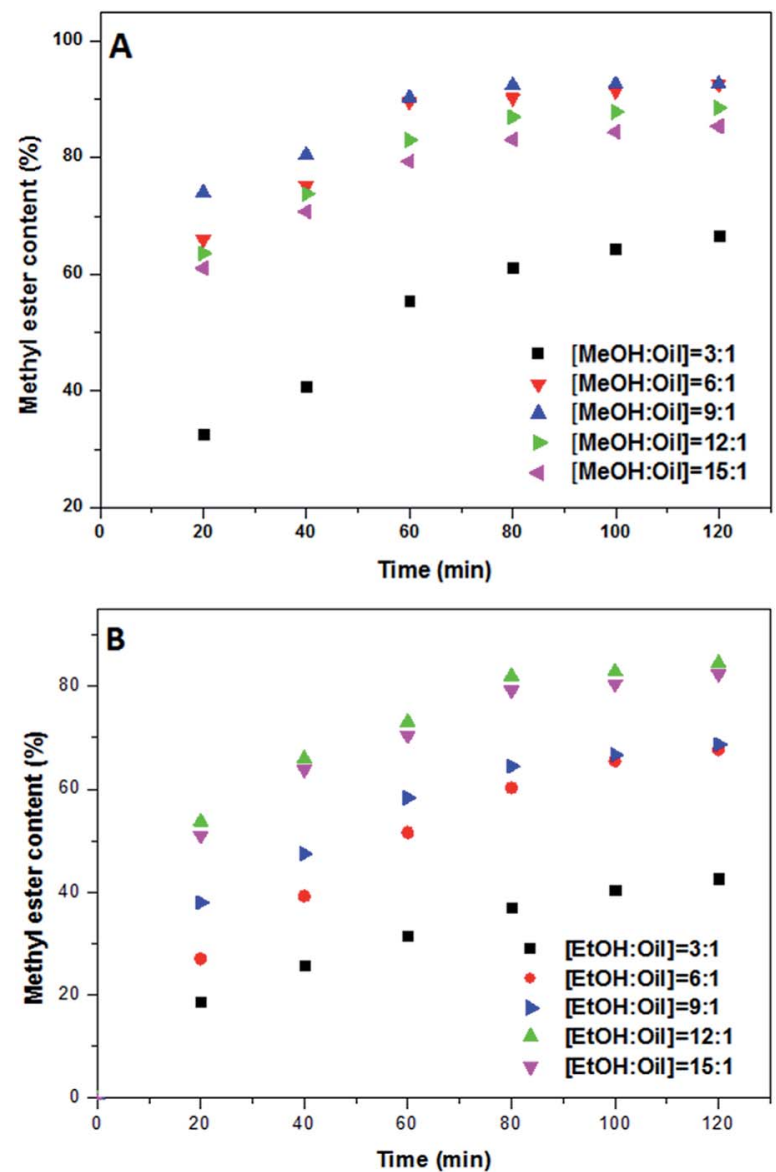

Fig. 6 The effect of carbon length of alcohol; (A) methanol and (B) ethanol on the FAME yield versus operating time (the catalyst amount, alcohol to WCPO molar ratio, operating temperature and mixing intensity were $1.0 \mathrm{wt} \%, 80^{\circ} \mathrm{C}$ and $300 \mathrm{rpm}$, respectively). 
became more complex over higher alcohol ratios. ${ }^{2}$ The higher ratio of alcohol is not recommended as the excess amount of alcohol adsorbed on the surface of the catalyst, resulted in deactivation of the catalyst. Besides, further increasing in the methanol ratio caused flooding of active sites which prevented entirely protonation of FFAs at the active sites. Results proved that gaining higher conversion in lower methanol : oil was more possible which corresponded to better absorption capability of methanol (due to its polar properties) in comparison with ethanol.

3.2.3. Effect of reaction temperature. The impact of operating temperature on catalytic activity of the synthesized sulfonated mesoporous NiO-ICG catalyst was examined at various temperatures $\left(60,80,100,120,140{ }^{\circ} \mathrm{C}\right)$. Other reaction parameters including catalyst concentration, $\mathrm{MeOH}$ : WCPO molar ratio, and mixing intensity were $1.0 \mathrm{wt} \%, 9: 1$, and $300 \mathrm{rpm}$, respectively. Fig. 7 displays the impact of operating temperature on the conversion yield. It was observed that by increasing the operating temperature from $60{ }^{\circ} \mathrm{C}$ to $80{ }^{\circ} \mathrm{C}$, the initial FAME yield increased and further increasing on the temperature up to $100{ }^{\circ} \mathrm{C}$, resulted in highest biodiesel yield (probably equilibrium was achieved) while by increasing the temperature above $100{ }^{\circ} \mathrm{C}$, the FAME yield decreased. Since the operation via hydrothermal-autoclaving technique was done under a sealed system over HTHP conditions, the loss of methanol was avoided while evaporated methanol forced back to the reaction phase. On the other hand, increasing in the reaction temperature above the equilibrium point may cause the formation of a large quantity of bubbles which may interfere the catalysis reaction. Results were in line with previous research where transesterification of groundnut oil with methanol was examined in presence of methanol over sulfated niobia supported on KIT-6 catalyst at various temperatures (100, 120, 150 and $\left.170{ }^{\circ} \mathrm{C}\right) .{ }^{32}$ The optimum operating temperature was found to be at $150{ }^{\circ} \mathrm{C}$, however, further increasing above optimal temperature caused reduction in FAME yield. By drawing on the results, the optimum reaction temperature was found to be $100{ }^{\circ} \mathrm{C}$ with the FAME yield of $94.11 \%$.

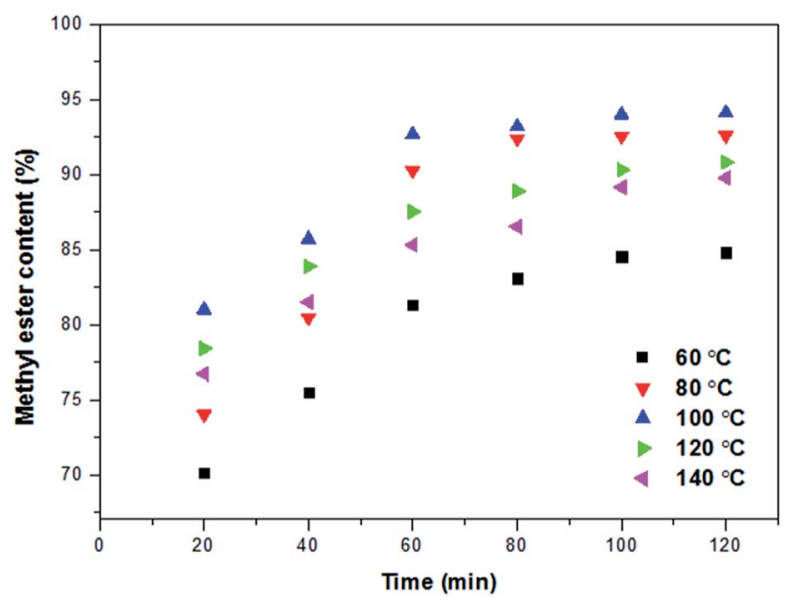

Fig. 7 The effect of operating temperature on the FAME yield versus operating time (the catalyst concentration, $\mathrm{MeOH}$ : WCPO molar ratio, and mixing intensity were $1.0 \mathrm{wt} \%, 9: 1$, and $300 \mathrm{rpm}$, respectively).
3.2.4. Effect of mixing intensity. The effect of different mixing intensities $(200,300,400,500$, and $600 \mathrm{rpm})$ on the yield of methyl ester were investigated. The effect of mixing intensity on the conversion yield is depicted in Fig. 8, where the catalyst dosage, $\mathrm{MeOH}$ : WCPO molar ratio, and operating temperature were $1.0 \mathrm{wt} \%, 9: 1$, and $100{ }^{\circ} \mathrm{C}$, respectively. Obviously, when the mixing intensity was at the lowest rate $(150 \mathrm{rpm})$, the conversion rate was very low. By increasing mixing power to $450 \mathrm{rpm}$, the highest conversion yield of $95.6 \%$ was attained. However, the FAME yield was almost same with further increasing in the mixing intensity, which was similar with previous reports. ${ }^{33}$ The higher mixing intensity might cause to sticking of the catalyst particles to the Teflon cup which kept them out of the reaction. Therefore, the optimal mixing intensity was found to be $450 \mathrm{rpm}$.

\subsection{Recyclability of the sulfonated NiO-ICG catalyst during ester production}

It should be noted that diffusion of the polar by-products to the surface of the catalyst causes deactivation of the catalyst. ${ }^{7}$ As a consequence, recyclability of the catalyst is a matter interest. In comparison with environmentally unfriendly homogeneous acid catalysts, reusable ecofriendly solid acid catalysts can be simply regenerated and recycled which significantly reduce the cost of production. ${ }^{\mathbf{8} 9}$ The recyclability of the sulfonated mesoporous NiO-ICG catalyst was tested through ester production using autoclave-assisted reactor within $80 \mathrm{~min}$ when the $\mathrm{MeOH}$ : WCPO molar ratio was $9: 1$, catalyst loading was $1.0 \mathrm{wt} \%$, reaction temperature was $100{ }^{\circ} \mathrm{C}$, and mixing intensity was $450 \mathrm{rpm}$. As the reaction was ended, the spent catalyst was separated and then washed with a mixture of hexane and ethanol to get rid of adsorbed compounds on the active sites, and finally it was dried in an electrical vacuum oven during the night at $100{ }^{\circ} \mathrm{C}$. According to the recyclability results, the content of WCPO methyl ester was found to be $95.6 \%, 95.3 \%$, $94.5 \%, 93.7 \%, 91.7 \%, 88.1 \%, 85.4 \%, 80.7 \%$ and $75.9 \%$ while the sulfonated mesoporous NiO-ICG catalyst was applied for nine

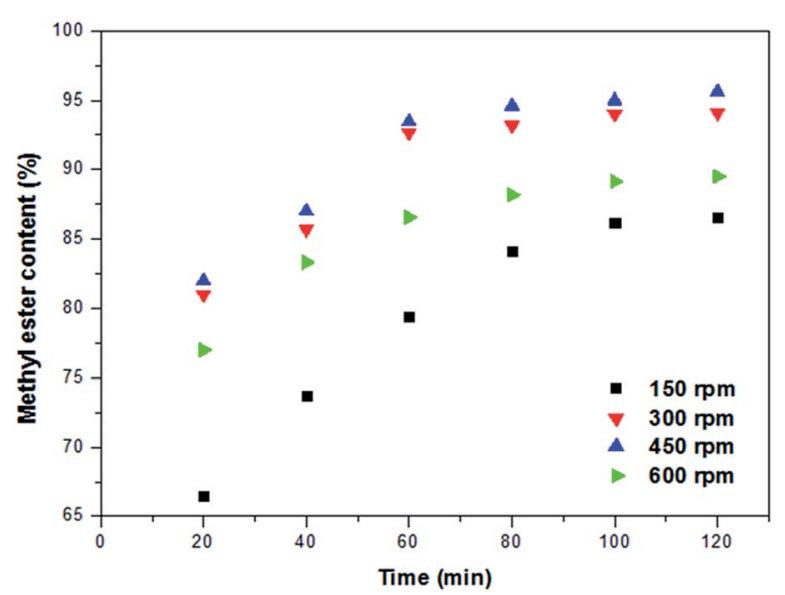

Fig. 8 The effect of mixing intensity on the FAME yield versus reaction time (the catalyst concentration, $\mathrm{MeOH}$ : WCPO molar ratio, and operating temperature were $1.0 \mathrm{wt} \%, 9: 1$, and $100{ }^{\circ} \mathrm{C}$, respectively). 
repeated transesterification reactions (illustrated in Fig. 9). The leaching of the active species was determined by CHNSelemental analyser. The CHNS results showed slight reduction of the sulfur content from $1.80 \mathrm{wt} \%$ to $1.33 \mathrm{wt} \%$ for the first to ninth transesterification runs, respectively. Obviously, the loss of activity in each run was very insignificant which meant that the leaching had not affected the bonded sulfuric acid compounds and inner pore walls. The high catalytic activity through reusability process may be corresponded to (i) excellent textural and structural properties of the synthesized sulfonated mesoporous NiO-ICG catalyst and (ii) covalently attachment of the sulfonic groups into the inner surface of the mesostructured catalyst through post-sulfonation by thermal decomposition of ammonium sulphate. As can be seen in Fig. 9, the catalytic activity gradually decreased $(19.7 \%)$ over nine continuous reactions which might be due to blockage of the mesopore channels (as a result of chemisorption of reactants on the active sites), formation of sulfonate ester, or slight leaching of the sulfonic components. ${ }^{34,35}$

\subsection{Fuel characteristics of the synthesized WCPO methyl ester}

Table 3 depicts fuel characteristics of the synthesized WCPO methyl ester in comparison with American Standard Testing and Materials (ASTM) and European Nation (EN) standards. The fuel properties were investigated to determine that the synthesized ester possessed adequate value to be used as biofuel in accordance with those of ASTM; D6751 and EN; 14214 specifications.

3.4.1. Density. The density has huge impact on the atomization of the oil through combustion system especially in airless condition. According to those of ASTM; D6751 and EN; 14214 specifications, the biofuel must have a density within range of $0.83-0.93 \mathrm{~g} \mathrm{~cm}^{-3}$. From the results, the

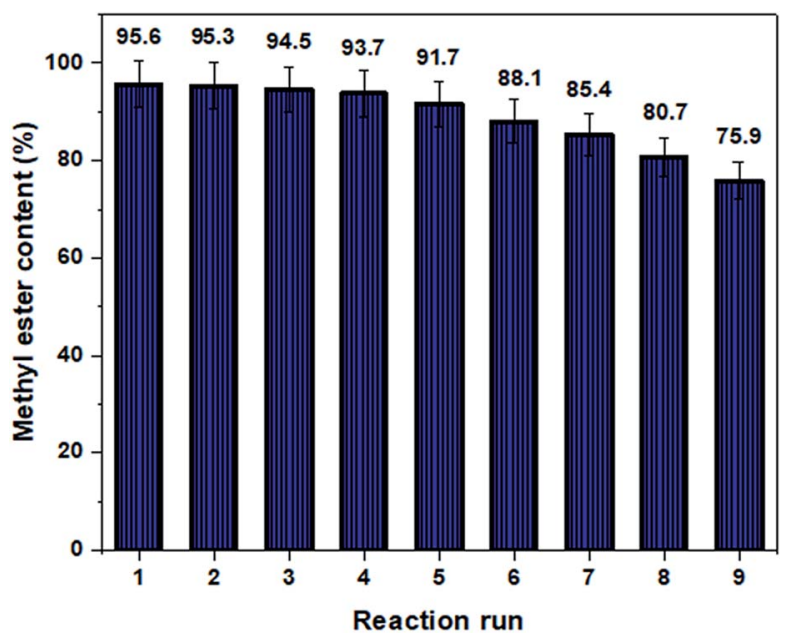

Fig. 9 The reusability of the mesoporous sulfonated mesoporous NiO-ICG catalyst for nine cycles under optimum transesterification conditions: $\mathrm{MeOH}$ : WCPO molar ratio of $9: 1$; catalyst loading of 1.0 wt\%; operating temperature of $100{ }^{\circ} \mathrm{C}$; and mixing intensity of $450 \mathrm{rpm}$. density of the synthesized ester was $0.86 \mathrm{~g} \mathrm{~cm}^{-3}$ which was lower than the density of the WCPO feedstock.

3.4.2. Kinematic viscosity. The kinematic viscosity (KV) is a parameter which strongly related to the fatty acid components of the fuel. According to those of ASTM; D6751 and EN; 14214 specifications, the KV of the biodiesel must be within range of $1.9-6.0 \mathrm{~mm}^{2} \mathrm{~s}^{-1}$ and $3.5-5.0 \mathrm{~mm}^{2} \mathrm{~s}^{-1}$, respectively. From the results, the $\mathrm{KV}$ of the produced biodiesel was measured $\left(4.10 \mathrm{~mm}^{2} \mathrm{~s}^{-1}\right)$ which was extremely lower than the viscosity of the WCPO feedstock $33.0 \mathrm{~mm}^{2} \mathrm{~s}^{-1}$.

3.4.3. Acid value. The acid value (AV), which affects the fuel aging, shows the FFAs content in the biodiesel. The hydrolytic cleavage of the methyl ester bonds might increase the value of FFAs content, results in the corrosion of the metal part in the engine because of high melting point of FFAs. According to those of ASTM; D6751 and EN; 14214 standards, the AV of the ester must be maximum $0.5 \mathrm{mg}$ $\mathrm{KOH}$ per $\mathrm{g}$. The AV of the synthesized WCPO methyl ester was $0.30 \mathrm{mg} \mathrm{KOH}$ per $\mathrm{g}$, which was within specifications range.

3.4.4. Water content. The biodiesel which is contaminated with moisture may cause the corrosion of the engine in metal parts. Moreover, molecules of water may interact with glycerides in the fuel, results in the formation of soap which definitely interferes the smooth pumping of the fuel. In this regard, the ASTM; D6751 and EN; 14214 standards specified a maximum value of $0.05 \%$ of the water in the fuel. From the results, the water content of the synthesized ester was in the range of specification.

3.4.5. Cold flow properties. The cloud point (CP) and pour point (PP) are two of the most important cold flow features of the fuels. The cloud point is an evaluation of the oil temperature, at which point the oil starts solidifying. The pour point is an evaluation of the oil, at which point the oil starts flowing. According to the of ASTM; D6751 specification, the $\mathrm{CP}$ and $\mathrm{PP}$ of the ester must be within range of $-3{ }^{\circ} \mathrm{C}$ to $12{ }^{\circ} \mathrm{C},-15{ }^{\circ} \mathrm{C}$ to $12{ }^{\circ} \mathrm{C}$, respectively. However, the $\mathrm{EN} ; 14214$ standards have not specified any limitations for those of CP and PP because the world's climate condition is very considerable. ${ }^{36}$ The CP and PP of the produced WCPO methyl ester were found $-6{ }^{\circ} \mathrm{C}$ and $-9.5{ }^{\circ} \mathrm{C}$, respectively which were in range of ASTM; D6751 specification.

3.4.6. Flash point. The flash point (FP) is a measure of the oil temperature, at which point the oil starts to vaporize via measured lab condition. In case of fuel management and safety, especially in fuel transportation and storage, determination of the FP is extremely important. Obviously, fuels which possess higher FP value are able to highly reduce the risk of combustion. However, the higher flash point of the biodiesel is a considerable advantage of biodiesel as compared with petroleum-based fuel. From the results, the FP of the synthesized WCPO methyl ester was found to be $180{ }^{\circ} \mathrm{C}$ which was within specified range of those ASTM; D6751 and EN; 14214 standards. 
Table 3 Fuel properties of the synthesized WCPO methyl ester over the sulfonated mesoporous NiO-ICG catalyst $^{b}$

\begin{tabular}{|c|c|c|c|c|}
\hline Parameters & WCPO methyl ester & EN 14214 & ASTM D6751 & Diesel \\
\hline Cloud point $\left({ }^{\circ} \mathrm{C}\right)$ & $-6.0 \pm 1.30$ & ${ }^{a} \mathrm{NS}$ & $-3-12$ & ${ }^{a} \mathrm{NS}$ \\
\hline Pour point $\left({ }^{\circ} \mathrm{C}\right)$ & $-9.5 \pm 0.20$ & ${ }^{a} \mathrm{NS}$ & $-15-12$ & ${ }^{a} \mathrm{NS}$ \\
\hline Flash point $\left({ }^{\circ} \mathrm{C}\right)$ & $176 \pm 2.00$ & $120 \mathrm{~min}$ & $130 \mathrm{~min}$ & 68 \\
\hline Kinematic viscosity at $40^{\circ} \mathrm{C}\left(\mathrm{mm}^{2} \mathrm{~s}^{-1}\right)$ & $4.10 \pm 0.10$ & $3.5-5.0$ & $1.9-6.0$ & 2.6 \\
\hline Acid value (mg KOH per $\mathrm{g}$ ) & $0.30 \pm 0.05$ & $0.5 \max$ & $0.5 \max$ & 0.35 \\
\hline
\end{tabular}

${ }^{a}$ Not specified. ${ }^{b}$ Values are mean \pm standard deviation of triplicate determinations.

\section{Conclusion}

The current research has shown that the synthesized sulfonated mesoporous NiO-ICG catalyst was highly potential to convert spent WCPO into methyl ester over hydrothermal assisted method. The best possible conversion rate of $95.6 \%$ was attained over optimal operating conditions; catalyst dosage of $1.0 \mathrm{wt} \%$, MeOH-WCPO molar ratio of $9: 1$, operating temperature of $100{ }^{\circ} \mathrm{C}$ and mixing intensity of $450 \mathrm{rpm}$. Nevertheless, the use of WCPO ridiculously diminished the biodiesel production cost. According to the recyclability results, the recycled catalyst possessed excellent catalytic performance for nine repeated reaction runs with negligible loss of activity. The excellent recyclability of the synthesized catalyst was assigned to the excellent textural and structural properties of the synthesized sulfonated mesoporous NiO-ICG catalyst, covalently attachment of the sulfonic groups into the inner surface of the mesostructured catalyst through post-sulfonation by thermal decomposition of ammonium sulphate. Furthermore, the physicochemical characteristics of the produced WCPO methyl ester were assessed which were highly in line with those of EN; 14214 and ASTM; D6751 specifications.

\section{Conflicts of interest}

There are no conflicts to declare.

\section{Acknowledgements}

The authors extend their appreciation to Universiti Putra Malaysia (UPM) for funding this research work through Geran Putra (UPM/2016/9515201, GP-IPB/2016/9515200 and GP-IPB/ 2016/9515202). We also would like to convey deepest gratitude and appreciation to Dr Maryam Shad for her ceaseless support.

\section{References}

1 B. H. Hameed, L. F. Lai and L. H. Chin, Fuel Process. Technol., 2009, 90, 606-610.

2 K. Noiroj, P. Intarapong, A. Luengnaruemitchai and S. Jai-In, Renew. Energy., 2009, 34, 1145-1150.

3 C. M. Garcia, S. Teixeira, L. L. Marciniuk and U. Schuchardt, Bioresour. Technol., 2008, 99, 6608-6613.
4 K. F. Yee, J. C. S. Wu and K. T. Lee, Biomass Bioenergy, 2011, 35, 1739-1746.

5 S. Soltani, U. Rashid, I. A. Nehdi and S. I. Al-Resayes, Chem. Eng. Technol., 2017, 40, 1931-1939.

6 S. Soltani, U. Rashid, R. Yunus, Y. H. Taufiq-Yap and S. I. AlResayes, Renew. Energy., 2016, 99, 1235-1243.

7 V. B. Veljkovic, S. H. Lakicevic, O. S. Stamenkovic, Z. B. Todorovic and M. L. Lazic, Fuel, 2006, 85, 2671-2675.

8 F. Guo, Z. Fang, C. C. Xu and R. L. Smith, Prog. Energy Combust. Sci., 2012, 38, 672-690.

9 J. H. Clark and J. D. Macquarrie, Chem. Commun., 1998, 8, 853-860.

10 J. Zhao, Y. Yue, W. Hua, H. He and Z. Gao, Appl. Catal., A, 2008, 336, 133-139.

11 Q. Shu, Q. Zhang, G. Xu, Z. Nawaz, D. Wang and J. Wang, Fuel Process. Technol., 2009, 90, 1002-1008.

12 Z. Gao, S. Tang, X. Cui, S. Tian and M. Zhang, Fuel, 2015, 140, 669-676.

13 C. Kordulis, K. Bourikas, M. Gousi, E. Kordouli and A. Lycourghiotis, Appl. Catal., B, 2016, 181, 156-196.

14 V. Itthibenchapong, A. Srifa, R. Kaewmeesri, P. Kidkhunthod and K. Faungnawakij, Energy Convers. Manage., 2017, 134, 188-196.

15 S. Zulkepli, J. C. Juan, H. V. Lee, N. S. A. Rahman, P. L. Show and E. P. Ng, Energy Convers. Manage., 2018, 165, 495-508.

16 M. Yoshimura and K. Byrappa, J. Mater. Sci., 2008, 43, 20852103.

17 H. J. Cho, J. K. Kim, S. W. Hong and Y. K. Yeo, Fuel Process. Technol., 2012, 104, 271-280.

18 A. Z. Alothman, Materials, 2012, 5, 2874-2902.

19 H. Ahmad, S. Soltani, K. Thambiratnam, M. Yasin, M. F. Ismail and Z. C. Tiu, J. Mod. Opt., 2018, 65, 2339-2349.

20 A. Harith, S. Soltani, M. F. Ismail, K. Thambiratnam, C. W. Yi and M. Yasin, Laser Phys., 2018, 28, 76001.

21 A. Harith, S. Soltani, K. Thambiratnam and M. Yasin, Opt. Eng., 2018, 57, 56110-56119.

22 H. Yan, D. Zhang, J. Xu, Y. Lu, Y. Liu and K. Qiu, Nanoscale Res. Lett., 2014, 9, 424.

23 C. Dong, X. Xiao, G. Chen, H. Guan, Y. Wang and I. Djerdj, RSC Adv., 2015, 5, 4880-4885.

24 C. Dong, X. Xiao, G. Chen, H. Guan, Y. Wang and I. Djerdj, RSC Adv., 2015, 5, 4880-4885. 
25 A. M. Dehkhoda, A. H. West and N. Ellis, Appl. Catal., A, 2010, 382, 197-204.

26 L. J. Konwar, P. Mäki-Arvela, E. Salminen, N. Kumar, A. J. Thakur and J. P. Mikkola, Appl. Catal., B, 2015, 176177, 20-35.

27 J. A. Melero, L. F. Bautista, G. Morales, J. Iglesias and R. Sánchez-Vázquez, Chem. Eng. J., 2010, 161, 323-331.

28 X. Liang, H. Xiao and C. Qi, Fuel Process. Technol., 2013, 110, 109-113.

29 K. Jacobson, R. Gopinath, L. Meher and A. Dalai, Appl. Catal., $B, 2008,85,86-91$.

30 A. I. Tropecêlo, C. S. Caetano, M. Caiado and 36 U. Rashid and F. Anwar, Fuel, $2008,87,265-273$. J. E. Castanheiro, Energy Sources, 2016, 38, 174-182.
31 C. S. Caetano, L. Guerreiro, I. M. Fonseca, A. M. Ramos, J. Vital and J. E. Castanheiro, Appl. Catal., A, 2009, 359, 4146.

32 K. Subramaniyan and P. Arumugam, J. Porous Mater., 2016, 23, 1-8.

33 G. D. Yadav and K. M. Devi, Chem. Eng. Sci., 2004, 59, 373383.

34 S. Soltani, U. Rashid, I. A. Nehdi, S. I. Al-Resayes and A. H. AlMuhtaseb, J. Taiwan Inst. Chem. Eng., 2017, 70, 219-228.

35 S. Kang, J. Chang and J. Fan, Chin. J. Chem. Eng., 2014, 22, 392-397. 